\title{
LA CREACIÓN DE EVA Y LA PIEDAD: DOS OBRAS DE PARRADO
}

\author{
Por \\ JULIA JIMÉNEZ GARCÍA
}

El escultor Eduardo Parrado Conde, que fue discípulo directo de Francisco Asorey, fue condenado al olvido por todos aquellos historiadores que se han acercado al estudio del arte contemporáneo gallego.

Sabemos que no es una figura relevante de nuestras artes plásticas ni tampoco es uno de los personajes que aparecerán formando parte de los grandes eventos culturales que últimamente se vienen celebrando en nuestra tierra, claro que esto también puede venir dado, tal vez en parte, por la propia personalidad del escultor dominada por ciertas, llamémosles «manías», como es la de consagrar toda su vida a trabajar la piedra y, en menor medida, el bronce, la madera o el mármol, y con aquellos mismos utensilios y técnicas que había aprendido al lado de su maestro, como la de renunciar voluntariamente a aquellos medios que le permitirían que su escultura trascendiese como hubiera merecido y que le llevasen a figurar en la bibliografía de la Historia del Arte. Claro que Parrado nunca lo buscó, nunca tuvo tal pretensión este hombre lleno de humildad y de sentimiento religioso, y quizá en esa línea humilde tengamos que apoyarnos para explicar las dos obras que son objeto de estudio y análisis de este artículo.

Parrado, como se le conoce habitualmente, discípulo y continuador de aquella escuela creada por Francisco Asorey, que se engloba dentro de un «primitivismo costumbrista» ${ }^{1}$ refleja en dos de sus obras, «La creación de

${ }^{1}$ LÓPEZ VÁZQUEZ, J.M.: La generación de 1885 en Enciclopedia temática de Galicia. Ediciones Nauta, 1988, Vol. V, p. 164.

"CUADERNOS DE ESTUDIOS GALLEGOS", Tomo XLVII, Fascículo 112, Santiago 2000. 
Eva» y en «La Piedad», un quehacer que no ha sido continuado por nuestro artesano, destacando mucho más en la primera en relación con lo mencionado anteriormente pero que sin embargo podría haberle ofrecido otras posibilidades escultóricas en cuanto a metodología, pero no creemos que en temática pues Parrado es un hombre de fuertes raíces y costumbres muy vinculadas a la tierra y al mundo gallego.

Tal vez Parrado no tuviera conocimiento de pertenecer de alguna manera, al «primitivismo costumbrista» que desarrolló su maestro, pero en la escultura de «La creación de Eva» hay una serie de características que nos hablan de unas cualidades que se ven unidas en este artesano de la piedra $\mathrm{y}$ tal vez ese «primitivismo» surge del modo concreto de trabajar, del material empleado, el granito, o como iniciativa propia del artesano que pretende que el tema resalte sobre la imagen, algo que se explicará a lo largo de este desarrollo.

Hay un «primitivismo» en la manera de esculpir y tallar (en gran medida motivado por el material granítico, ya mencionado), que se observa sobre todo en ciertas partes, como la mano de Dios, una mano esquemática, de cuatro dedos que sostienen la figura femenina y en la que distinguimos la anatomía por la presencia de unas líneas que la delimitan y por el granulado que rodea a la imagen de dicha mano. Pero este "primitivo» quehacer también se observa en las distintas partes de la figura femenina (manos, busto, rostro y cabello), con un sobrio volumen.

Y es que Parrado sólo ha pretendido destacar aquellas partes más notables dentro del cuerpo de la mujer, y sobre todo aquella que se considera más «pecaminosa», pero que, a la vez, es de algún modo el centro donde se origina la vida, y Eva lo cubre como si fuera un tesoro.

Por otro lado, Eva parte de una figura geométrica ${ }^{2}$ de la que surge, el rombo, y con un trapecio como base, pero a pesar de surgir del bloque, como los antiguos egipcios, Parrado le ha imprimido un carácter volumétrico, en gran medida somero, aunque usando la luz como medio diferenciador, podemos ver los planos que hay (por ejemplo, entre las manos,

\footnotetext{
${ }^{2}$ Para observar otra posible influencia con su maestro Asorey, sobre las figuras geométricas y la consideración del volumen, ver LÓPEZ VÁZQUEZ, op. cit. p. 165, último párrafo.
}

"CUADERNOS DE ESTUDIOS GALLEGOS", Tomo XLVII, Fascículo 112, Santiago 2000. 


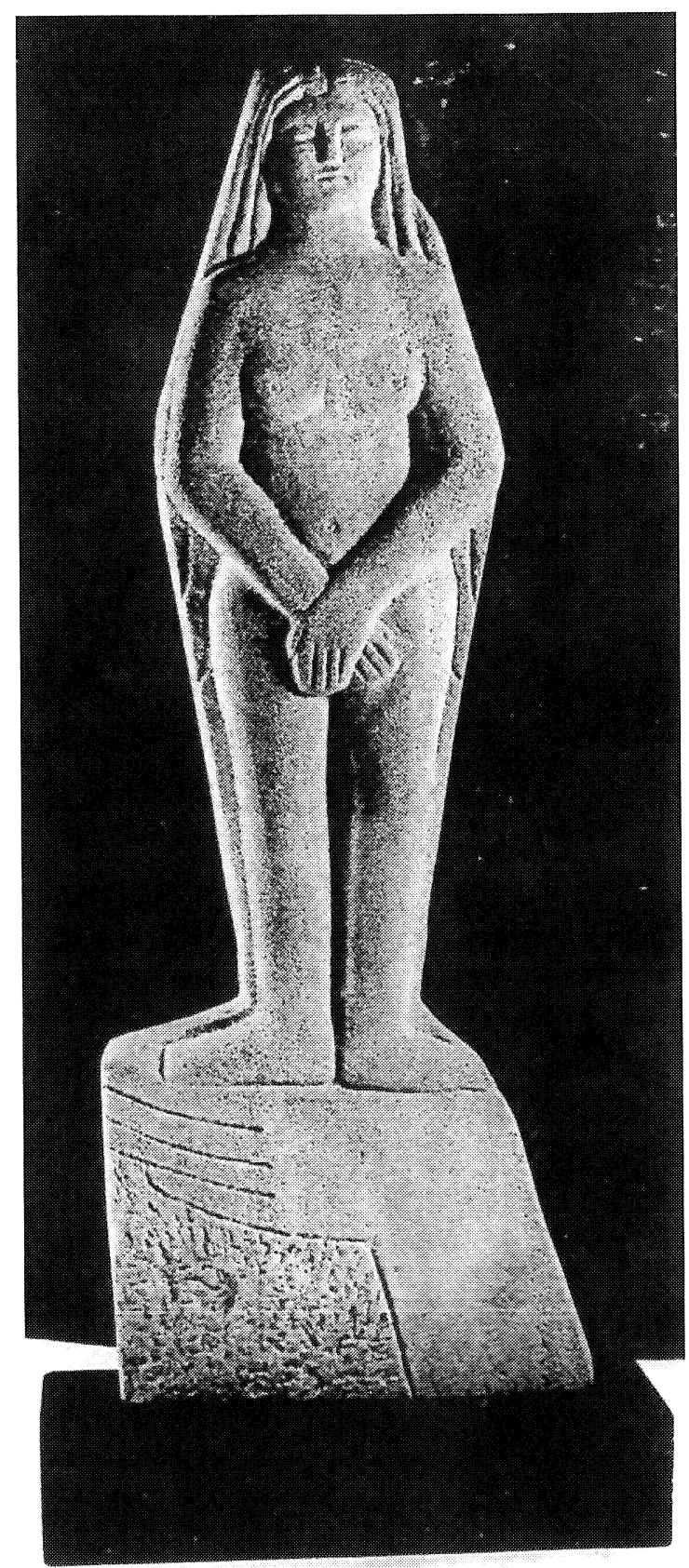

Fig. 1.- «La Creación de Eva», E. Parrado. 
evidentemente más avanzadas y el cuerpo, detrás de éstas); pero son planos que se igualan en volumen en ciertas zonas, como ocurre con los pies de Eva y la mano de Dios, llegando un punto en el que son definibles de la misma manera y sólo distinguibles por una simple línea. Esto nos habla de una falta de perspectiva, aunque también podría ser buscada, ya que Eva surge de la costilla de Adán por intervención divina ${ }^{3}$ y por lo tanto Parrado no ha plasmado la diferenciación necesaria que debería haber entre ambas partes.

El rostro, a pesar de ese esquematismo, es una parte notable; nos mira de modo indiferente, como asumiendo lo que ha de pasar, que pasará, o tal vez asumiendo la culpa del pecado cometido, ya que tiene constancia de su desnudez, puesto que se cubre como ya se mencionó. Es un rostro redondeado, que marca una línea vertical imaginaria con las manos que se tapan un rostro que posee características medievales, como los ojos, la frontalidad.

Tal vez ha intentado plasmar el momento de la concepción (no olvidemos que el nombre de Eva significa «madre de los vivientes» 0 « la que da la vida $\rangle^{4}$ ), apareciendo una similitud, que nunca equivalencia, entre la capacidad de dar vida que Dios tiene y la capacidad de concebirla, desarrollarla y traerla al mundo que Eva tiene. Por eso Eva aparece con una rostro atemperado, serio, por la gran responsabilidad que el mundo de Occidente le otorga en la religión cristiana.

Otro dato que conviene recordar de nuevo es que Asorey se vio influido por la corriente «primitivista» de la Europa finisecular ${ }^{5}$. Teniendo en cuenta este hecho en conjunto con el dato compartido de que la escultura que es objeto de análisis de este artículo se realizó en el taller de Santa Marta (entre los años 1955- 1960) ${ }^{6}$, cuando Parrado aún estaba trabajan-

\footnotetext{
${ }^{3}$ Génesis 2, 21-22.

${ }^{4}$ COSTA GONZÁLEZ, H.: Mil nomes galegos, trabajo realizado dentro de la campaña «En galego é de xustiza», 1991.

${ }^{5}$ LÓPEZ VÁZQUEZ, J. M.: op. cit. p. 165.

${ }^{6}$ Parrado no rememora el año concreto de la realización de la pieza, pero sí sabe que fue en su casa de Santa Marta (Campo de Santa Marta). Sabiendo que la casa se hizo en el año 1954 y que Parrado estaba mientras trabajando con Asorey en el taller de Santa Clara, es posible que la fecha de ejecución fuera ésta, siendo por ello una de las primeras obras del artista de creación e inspiración propia.
} 
do con Asorey en su taller de Santa Clara, nos explicaría por un lado ese «primitivismo técnico» (no olvidemos que es también una obra de pequeñas dimensiones y que esto ha debido de influir en su ejecución) y por otro lado, ese costumbrismo nacionalista que de un modo concreto y particular recoge la obra en su temática.

Todo este «primitivismo»y «esquematismo» del que venimos hablando no puede desligarse en manera alguna del tema que lo origina, una temática religiosa en todos los aspectos, y que se puede considerar costumbrista si tenemos en cuenta que la religión es algo que está muy arraigado en la cultura y tradición gallega; y hay que decir que también es algo inherente del propio Parrado, al cual siempre oiremos agradecer su vida a la «Divina Providencia» ${ }^{7}$.

El tema, como bien nos dice su título, es la «Creación de Eva» ${ }^{8}$, un tema que se considera medieval, teniendo en cuenta la concepción de «pecado» que por entonces había. No olvidemos la presencia de la mano de Dios, firme bajo los pies de la mujer, que nos la presenta seria, surgiendo del bloque, como ya se dijo antes.

Es una figura, con la cabeza erguida, con una aureola esquemática que recuerda los rostros románicos (ojos almendrados. Parrado, como él dice, se inspira en el románico. Y tal vez aquí encontró una apoyatura para realizar esta obra).

El granito también permite esa dureza de la forma figurativa. Un granito que no ha recibido la última fase, la del pulido. Dando así rudeza y textura a la obra. Una obra que nos pude recuerdar en ciertos aspectos, el beso de Brancusi (líneas y una temática que lo es todo).

Pero volviendo a la temática, Parrado ha plasmado a esta Eva como una venus púdica, consciente de su desnudez y que por lo tanto se tapa

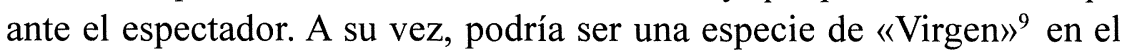
amplio sentido de la palabra, cubierta por un manto que, no es otro que su propio pelo, y que aún más le confiere ese carácter geométrico.

\footnotetext{
${ }^{7}$ Palabras textuales del escultor Parrado.

${ }^{8}$ Génesis op. cit.

${ }^{9}$ No nos atrevemos a usar la palabra «Inmaculada» por error de significado, aunque formalmente nos remita a ellas.
}

"CUADERNOS DE ESTUDIOS GALLEGOS", Tomo XLVII, Fascículo 112, Santiago 2000. 
Otra obra que nos ha llamado la atención es la «Piedad» que hizo Parrado y que recibió el premio de accésit a la Escuela de Artes y Oficios de Santiago de Compostela ${ }^{10}$.

Se trata de un grupo escultórico formado por tres figuras, dos mujeres y un hombre, María Madre, María Magdalena y Cristo Muerto, mientras que la obra anterior era solamente la figura de Eva, presente de un modo material, y la figura de Dios se presentaba a modo de metonimia (la parte por el todo) a través de la Mano Creadora.

Pero hay una serie de características que se pueden observar en las dos obras, aunque también hay diferencias. Así, en Eva veíamos una composición geométrica y en la «Piedad» de Parrado está presente el triángulo, otra figura que equilibra una composición que ya de por sí es emotivamente «desequilibrada», sentimentalmente hablando.

A su vez esta composición piramidal y cerrada, puesto que ambas mujeres miran el cuerpo del Fallecido y no hay ninguna vinculación con el espectador salvo la de ser mero observador, es dividida por una línea horizontal, cuyos extremos están marcados por la cabeza de Cristo y por las manos de María agarrando a su Hijo.

En esta obra Parrado también emplea el recurso de la peana. En la «Creación de Eva» la peana se incorpora a la temática, cumpliendo su faceta de resaltar la figura femenina, a la vez que es elemento narrativo y complementario de la misma. Pero la «Piedad» es el lugar idóneo para la colocación de las figuras que componen la obra, es donde María Madre y María Magdalena van a depositar el cuerpo de Cristo ${ }^{11}$.

A diferencia de la «Creación de Eva», en ésta las líneas son más sinuosas, más suaves y curvas, sobre todo en las figuras femeninas (obsérvense los mantos que cubren las cabezas). El cuerpo de Cristo ya tiene otra composición diferente: la cabeza está relajada y las rodillas, profundamente triangulares, están rígidas (aunque esto también podría ser a causa de que María Magdalena le está sujetando los pies). De todos modos, la rigidez y la laxitud son características de los cuerpos muertos y ésto nos hace pen-

\footnotetext{
${ }^{10}$ Parrado desconoce la fecha del concurso y nosotros hemos calculado que se realizaría anteriormente a la "Creación de Eva», pero también bajo la influencia de su maestro Francisco Asorey, pues trabajó en su taller desde el año 1936 ya en Santa Clara y bajo su tutela directa.

${ }^{11}$ Mateo 15, 47-47.
} 


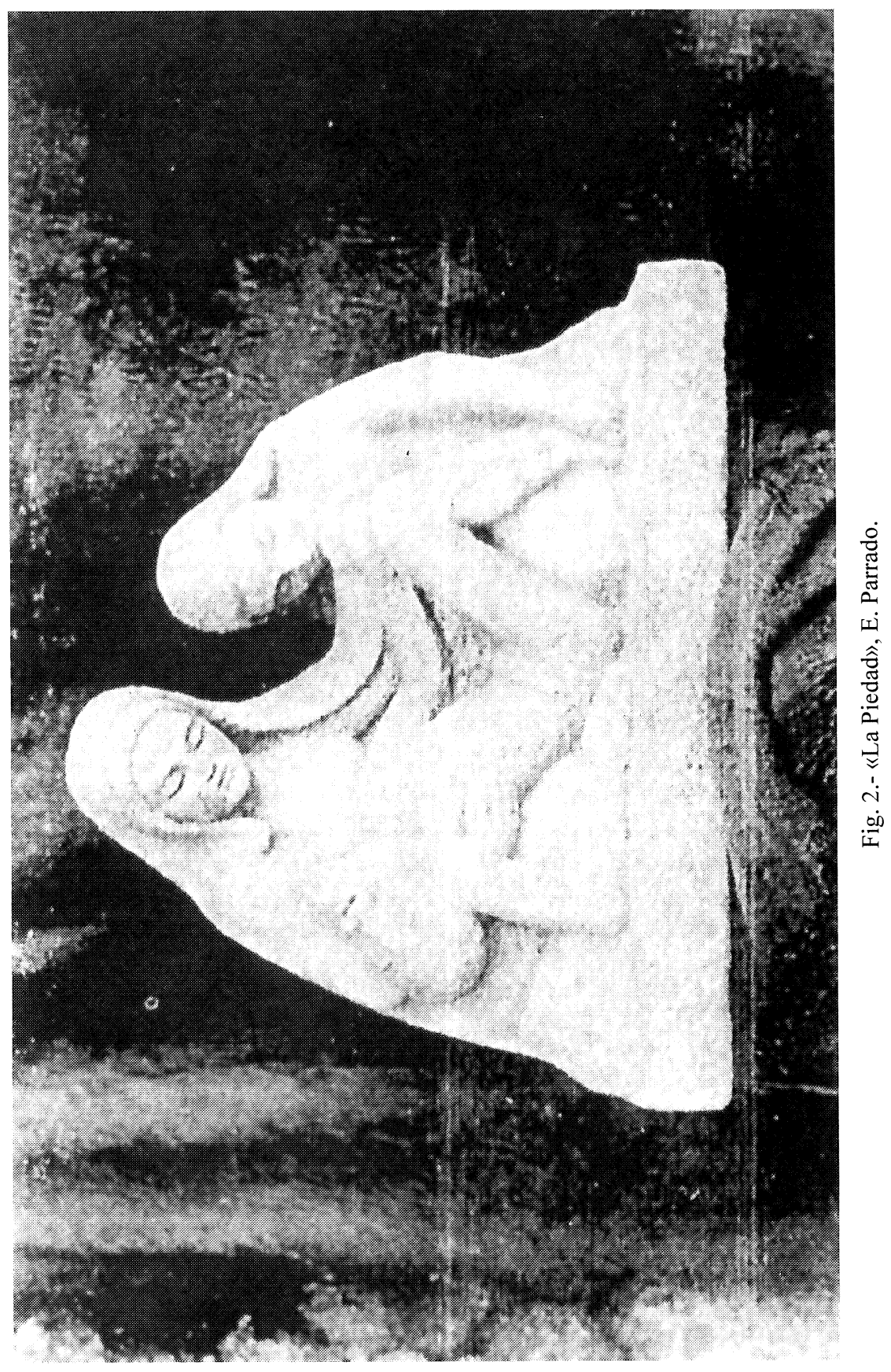

(c) Consejo Superior de Investigaciones Científicas 
sar que Parrado ha querido reflejar a un Cristo ya inerte. Claro está, es una Piedad, y en las piedades se nos representa a María con su Hijo falleci$\mathrm{do}^{12}$. Pero el dolor no es una temática que Parrado prefiera, de hecho, en todas las obras, a parte de las comentadas, no aparece el ciclo doloroso de María, sino el gozoso.

Siguiendo con nuestro análisis, esta no es una obra tan «primitivista» ni «esquemática» como la anterior y en ella se aprecia más dedicación y laboriosidad en el trabajo técnico pero se podría decir que es una obra con cierto aire de expresionismo, tal vez heredado de su maestro ${ }^{13}$. Así lo podemos ver en el rostro de Cristo antinaturalmente curvado hacía atrás con los ojos cerrados, la boca entreabierta, barba puntiaguda y pelo rizado, en el cuerpo y en el brazo que se apoya en el suelo, formando un triángulo y como si aún le quedara un pequeño aliento de vida.

Del mismo modo observamos influencias del mundo de lo medieval en cuanto a iconografía ${ }^{14}$, ya que los rostros de Parrado nos recuerdan los rostros de los tímpanos de las iglesias con los ojos almendrados (sólo que en este caso están cerrados) y boca delineada. Pero iconológicamente el tema es barroco por el sentimiento trágico que se representa y por ser temática preferida en esta época. Igualmente es románica la frontalidad y el hieratismo de la imagen así como la desproporción de las figuras (con respecto a María, Cristo posee unas medidas más reducidas). Esta desproporción también aparece en la «Creación de Eva» donde los brazos y la melena son más largos de lo habitual. Sin embargo, Eva es una figura estilizada y el grupo de la piedad aparece recogido.

El nexo fundamental de unión entre las dos obras es la representación de la mujer en ambos casos como madre (entendiendo la «Mater» de Asorey, pero diferenciándose en el tiempo, es decir, la «Mater» asoreyana ya ha dado a luz y la de Parrado sólo ha germinado). Pero se establecen una serie de antítesis. Eva acaba de concebir y María ha perdido a su hijo. El

${ }^{12}$ G. FATÁS, G.M. BORRÁS: Diccionario de términos de Arte. Alianza Editorial, Madrid, 1993. p. 190.

${ }^{13}$ OTERO TUÑEZ, R.: El escultor Francisco Asorey, homenaje de la universidad compostelana al gran artista en su 70 aniversario, 1959, p. 37.

${ }^{14}$ OTERO TÚÑEZ, R.: op.cit. p.38.

"CUADERNOS DE ESTUDIOS GALLEGOS", Tomo XLVII, Fascículo 112, Santiago 2000. 


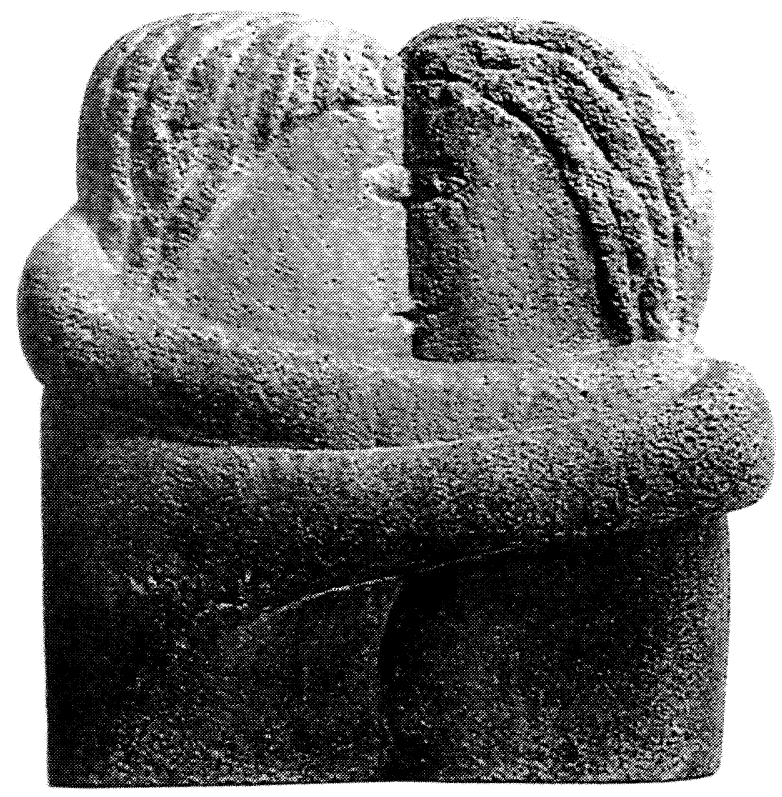

Fig. 3.- «El Beso», Brâncusi.

Constantin Brâncusi «El beso», escultura en piedra (1912). Filadelfia.

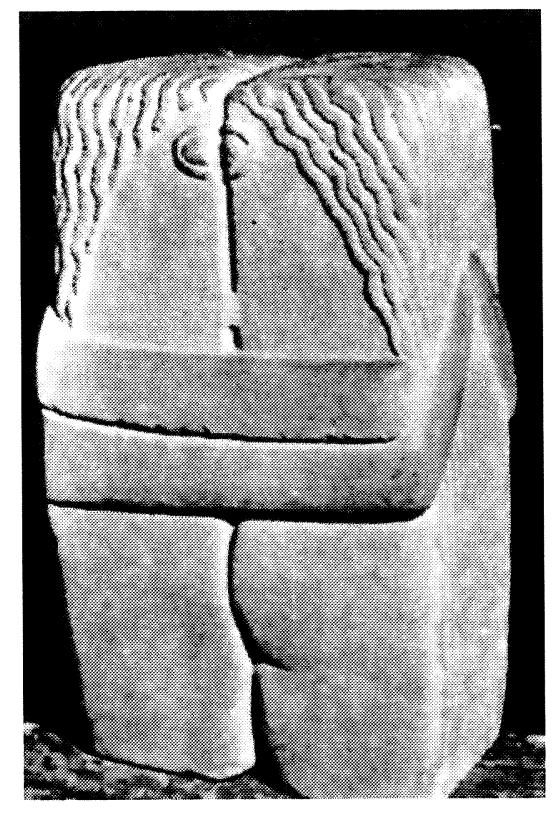


tema de la madre es un tema que Parrado ha cultivado insistentemente al igual que su maestro Asorey ${ }^{15}$, incluso el rostro de Eva nos recuerda levemente el de charitas $^{16}$.

Otro antagonismo sería que la primera está reflexionada como una "venus prehistórica», diosa de la fecundidad ${ }^{17}$ mayestática y erguida, y como tal, a pesar de ser consciente de su desnudez, es receptora del germen de la vida; en cambio en la «Piedad» aparece María que ha perdido a su hijo, pero que de un modo sereno e indulgente es capaz, sobre todo, de sostenerlo para despedirse de él. Y es que todos los rostros de Parrado que no son retratos, aparecen cargados de una gran dosis de tranquilidad y sosiego, tal vez proyección de su propio mundo interior, humilde y sencillo.

En ambas obras Parrado ha usado un material típicamente galaico, el granito, un granito que se niega a someterlo a la fase de pulido, con lo cual y lógicamente se nos ofrecen dos obras de gran fuerza táctil. Es una valoración de la materia que nace de la ejecución, a la que se somete al bloque para conseguir la obra, siempre, claro, sin borrar las huellas del proceso técnico, ya que lo que se pretende es plasmar algo que ha sido realizado por la mano del hombre, artesanal ${ }^{18}$.

Parrado siente gran admiración por su maestro, pero también ha agradecido siempre a su madre el hecho de poder ser escultor, con lo cual estas obras son una especie de homenaje al carácter generativo que poseen las mujeres. No olvidemos que es una temática religiosa la que se recoge en estas imágenes, pero también son una muestra de agradecimiento del escultor a la madre de la humanidad y a todas las madres de carne y hueso que por circunstancias sufren como sufrió María.

Con este desarrollo temático, sobre dos de las obras de este artesano de la piedra, hemos pretendido dar a conocer una faceta más de un hombre soberanamente trabajador que, como se dijo en un principio, no ha

${ }^{15}$ OTERO TUÑEZ, R.: Op. cit. p. 98.

${ }^{16}$ OTERO TUÑEZ, R.: Op. cit. lám. 19.

${ }^{17}$ MARTÍN GONZÁLEZ, J.J.: Historia del Arte, editorial Gredos, Madrid, 1992, p. 43.

${ }^{18}$ Parrado siempre se ha considerado ha si mismo como artesano de la piedra y así lo reconoce y lo mantiene llevandolo a la práctica en sus obras.

"CUADERNOS DE ESTUDIOS GALLEGOS", Tomo XLVII, Fascículo 112, Santiago 2000. 
tenido el merecido reconocimiento en los círculos del arte, y cuando ha sucedido lo contrario, siempre ha sido por sus «cruceiros» y escudos. Por ello, pretendemos demostrar la capacidad de este hombre para desarrollar temas desde un punto de vista muy personal.

Por último decir que ambas obras están en paradero desconocido ( «La Creación de Eva» pertenece, probablemente a una colección particular); de «La Piedad» realizó varias copias, pero nada más se ha podido saber de ellas. 